\title{
MELHORIA DO SISTEMA DE GESTÃO DA QUALIDADE*
}

Izabelle Lannes Salgueiro Ferreira ${ }^{1}$ Raphael Barbosa de Souza² José Carlos da Silva ${ }^{3}$

\section{Resumo}

O presente trabalho tem o objetivo de mostrar como sistemas especialistas melhoram a gestão da qualidade e processos ao trabalhar com grandes massas de dados, que são gerados continuamente pelos processos produtivos de laminação a quente.

Palavras-chave: Qualidade; Processo; Dados.

\section{IMPROVEMENT OF THE QUALITY MANAGEMENT SYSTEM}

\begin{abstract}
This work aims to show how expert systems improve quality management and processes when working with large data sets, which are generated continuously by the production processes of hot rolling.

Keywords: Quality; Process, Data.
\end{abstract}

1 Engenharia Metalúrgica UFF, Engenheira de Processo, Gerência de Laminação a Quente, Votorantim Siderurgia, Barra Mansa, Rio de Janeiro, Brasil.

2 Engenharia de Produção UniFOA, Operador de Painel, Gerência de Laminação a Quente, Votorantim Siderurgia, Barra Mansa, Rio de Janeiro, Brasil.

3 Técnico Mecânica, Técnico Especialista de Processo, Gerência de Laminação a Quente, Votorantim Siderurgia, Barra Mansa, Rio de Janeiro, Brasil. 


\section{INTRODUÇÃO}

Mercados cada vez mais competitivos e dinâmicos corroboraram com a implantação de sistemas de gestão especialistas para organizar a expressiva massa de dados que são gerados continuamente nos processos industriais.

Um sistema de gestão bem estruturado ajudará o corpo de responsáveis a otimizar as respostas aos problemas diários que surgem com as variações em processos complexos e altamente dinâmicos, como o processo de laminação a quente de perfis e vergalhões. Segundo o Handbook of Industrial Engineering Technology and Operations Management (Manual de Tecnologia da Engenharia Industrial e Gestão de Operações) um sistema de gestão que envolve a área de engenharia, tanto a de produto como a de processo e, quando envolve: pessoas, equipamentos e informações do processo produtivo é capaz de otimizar análises, avaliar dados do processo e ajudar nas tomadas de decisões com modelos de predições estabelecidos. O aperfeiçoamento dos sistemas de qualidade dentro das empresas é um fator importante para ser considerado visto que estamos nos adaptando a constates mudanças, que vão desde simples atendimento às normas técnicas até mesmo a um novo layout para aumentar a produtividade dos laminadores. Pequenas mudanças exigem um programa de acompanhamento e controle e um sistema de gestão deve fornecer esse suporte para que os dados sempre sejam organizados a fim de facilitar a gestão e análises de histórico e correlações, por exemplo.

O Programa de Qualidade, vem ao encontro do aperfeiçoamento do sistema de gestão, como uma melhoria dos sistemas já utilizados dentro da Gerência de Laminação a Quente da Votorantim Siderurgia da Unidade Barra Mansa. Ao encontro da definição de Bessant et al. (1994), de que a "melhoria contínua pode ser definida como um processo de inovação incremental, focada e contínua envolvendo toda a equipe" e na mesma linha de definição estratégica de Moura (1997), de que o primeiro passo para a busca da melhoria contínua é a implantação de um Sistema da Qualidade; desenvolvemos o Programa da Qualidade, um projeto piloto denominado ProQuali. O ProQuali é um programa que comunica com as etapas: processo de fabricação, controle ou inspeção online do produto e controle nos laboratórios de ensaios mecânicos; ou seja, o Sistema ProQuali integra todas as informações das três etapas citadas e organiza em um banco de dados todas as informações do processo de laminação a quente.

A vantagem é claramente observada com a velocidade no tratamento das informações, organização da grande massa de dados que são registrados continuamente e na otimização do tempo de análise dos problemas detectados, permitindo um espaço maior para a tomada de decisão e planejamento e acompanhamento das ações nos processos.

\section{MATERIAIS E MÉTODOS}

Como o ProQuali é um projeto piloto, foi considerado a perspectiva técnica e financeira para o desenvolvimento do programa. Tanto a propriedade intelectual como o software para o desenvolvimento do ProQuali já estavam disponíveis no Grupo de qualidade e, portanto, o custo para o desenvolvimento foi zero necessitando apenas de um planejamento da equipe em relação às agendas de cada integrante.

Foi utilizado como base de desenvolvimento o Visual Basic for Application (VBA) da Microsoft. Os recursos avançados de formulários, automação e controle de máquinas 
do VBA permitem que o programa seja robusto e totalmente rápido para administrar os dados em um banco de dados.

Após as reuniões de planejamento com a equipe, a macroestrutura do projeto ficou definida conforme a Tabela 1:

Tabela 1. Macroestrutura de desenvolvimento do ProQuali

\begin{tabular}{clcc}
\hline Item & Descrição & Tipo de Acesso & Controle \\
\hline 1 & Gestão de segurança dos dados & Restrito & Administrador \\
2 & Interface para gestão do processo produtivo & Livre & Livre \\
3 & Interface para gestão da inspeção online & Livre & Livre \\
4 & Interface para gestão do controle de ensaios & Livre & Livre \\
5 & Relatório operacional & Livre & Livre \\
6 & Relatório gerencial & Restrito & Gerencial \\
7 & Análises estatísticas & Livre & Livre \\
8 & Controle de alterações no ProQuali & Restrito & Administrador
\end{tabular}

O ProQuali foi desenvolvido na plataforma VBA atendendo todas as necessidades estabelecidas pela equipe do projeto, como:

- Facilidade de acesso;

- Controle e segurança dos dados;

- Interface amigável;

- Relatórios detalhados, porém otimizados;

- Gráficos dinâmicos e de fácil compreensão;

- Análises estatísticas que facilitem a tomada de decisão.

A Figura 1 mostra a tela inicial do ProQuali, onde observamos os menus iniciais de fácil acesso:

\begin{tabular}{|c|c|c|c|c|c|c|}
\hline \$) & ProQuali & Iniciar & Cadastros & Gráficos & Relatórios & Sair \\
\hline
\end{tabular}

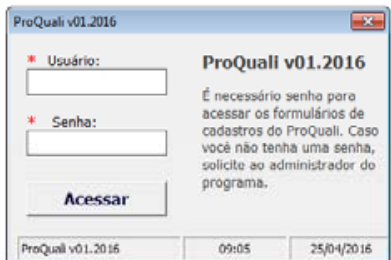

Figura 1: Tela inicial do ProQuali 


\section{RESULTADOS E DISCUSSÃO}

Os ganhos com o ProQuali foram avaliados em relação à capacidade de gerenciar uma grande massa de dados e fazer análises do processo em tempo real. Após a informatização das informações, todo o trabalho manual foi otimizado e organizado para dar mais eficácia em: gestão de processos, análises de falhas no processo, análise de campanhas, análise de reclamações de clientes e suporte para as auditorias interna e externa; sem custo para a área de desenvolvimento.

Com recursos avançados de análises, permitiu também a especialização dos colaboradores em métodos estatísticos e de análises de falhas.

As Figuras 2 e 3 mostram as telas para inputs de qualidade do produto e variáveis do processo, respectivamente:

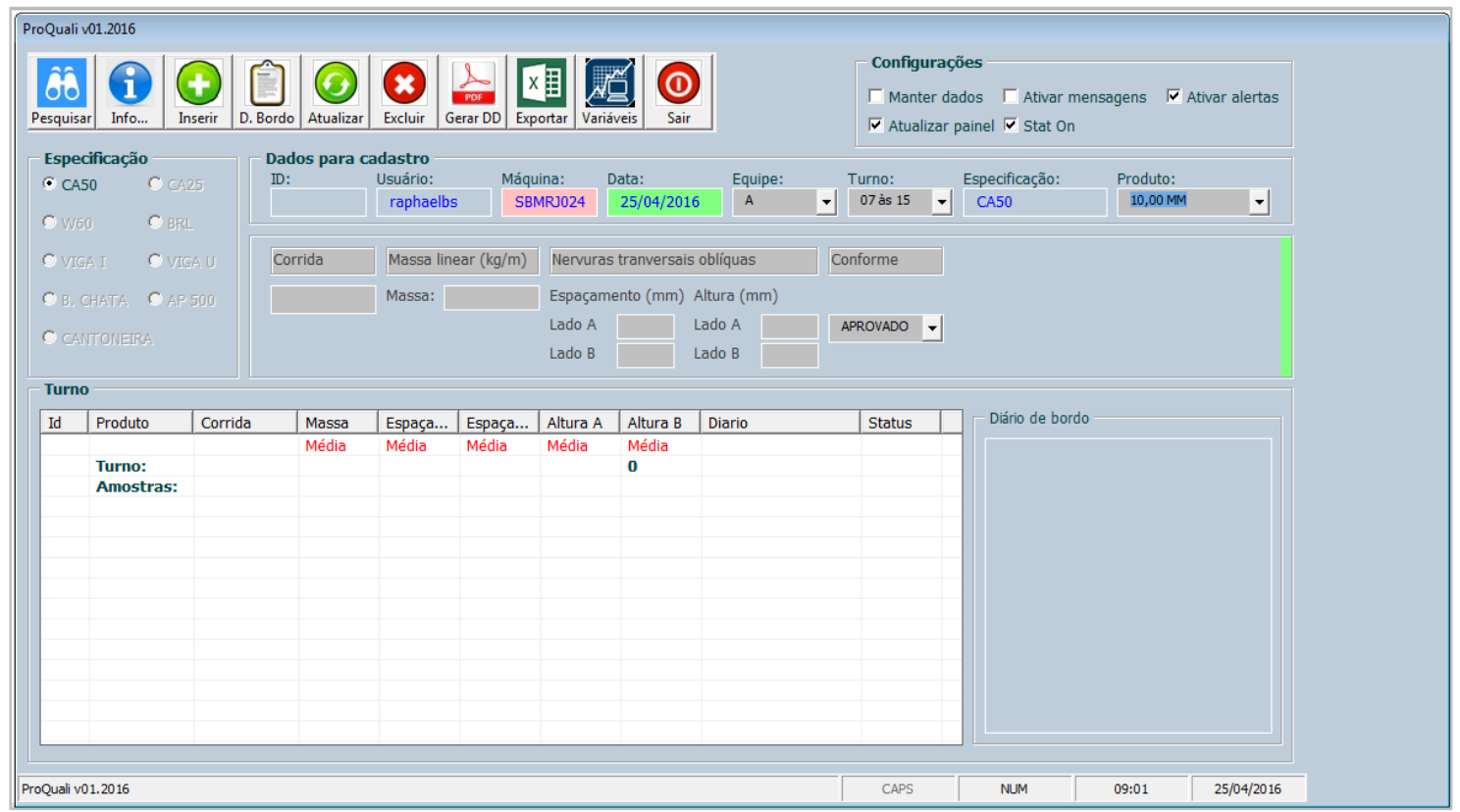

Figura 2: Tela para cadastro para as características do produto acabado

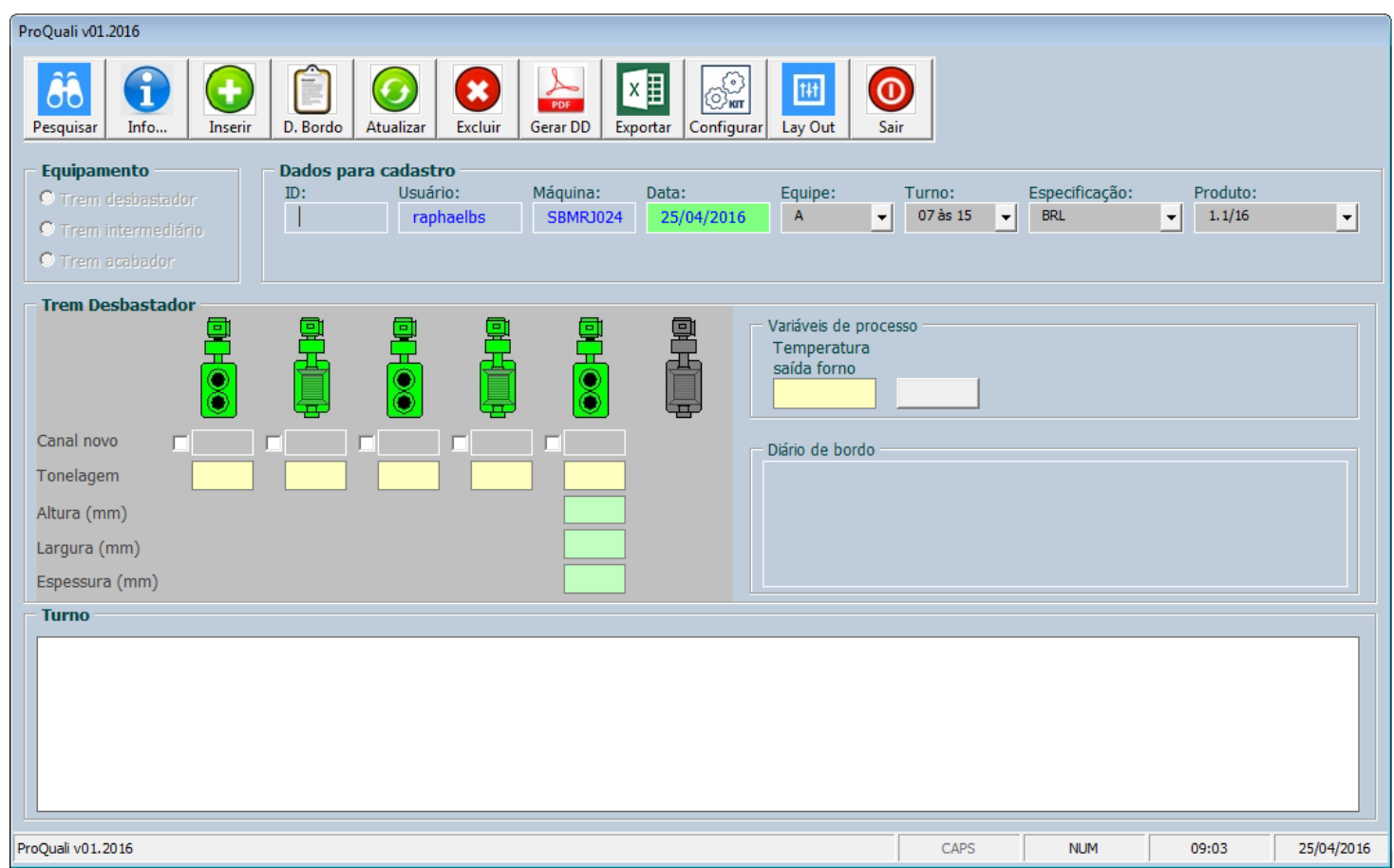

Figura 3: Tela para cadastro das variáveis do processo. 


\section{CONCLUSÃO}

O ProQuali foi cabalmente aceito pelos colaboradores da área como uma melhoria na gestão da qualidade e do processo; facilitou as análises do processo tanto para o nível tático como para o nível operacional do laminador.

Como um projeto piloto, o ProQuali está sendo utilizado como modelo base para a busca contínua por sistemas especialistas que garantam a otimização das análises e ganho no tempo de pesquisa com grandes massas de dados, um fator que na era da tecnologia da informação, se bem usado garante vantagem competitiva para as organizações.

\section{Agradecimentos}

Nossos sinceros agradecimentos à Votorantim Siderurgia pela oportunidade de desenvolver um programa da qualidade que possibilitasse a otimização dos nossos resultados e uma rápida análise para tomar decisões sobre o processo de laminação. Com a mesma importância, também agradecemos à nossa gerência pelo apoio e incentivo durante a caminhada do ProQuali e aos nossos colegas e colaboradores que apoiaram nosso projeto e aceitaram como uma melhoria para suas atividades diárias, relatando-nos que o ProQuali está "ajudando a analisar o processo com uma nova perspectiva".

Um agradecimento especial aos membros do time de desenvolvimento do ProQuali pela perseverança e a busca contínua por boas práticas ao lidar com os desafios encontrados durante o desenvolvimento do projeto piloto e o apoio com 0 conhecimento específico que contribui para o aperfeiçoamento da gestão da qualidade.

\section{REFERÊNCIAS}

1 SALVENDY, G. Handbook of Industrial Engineering: Technology and Operations Management. $3^{\mathrm{a}}$ ed. New York: Wiley, 2001.

2 BESSANT, J. et al. Rediscovering continuous improvement. Technovation. Elsevier, 1994.

3 MOURA, L. R. Qualidade simplesmente total: uma abordagem simples e prática da gestão da qualidade. Rio de Janeiro: Qualitymark, 1997. 